УДК 338

\title{
ЭФФЕКТИВНОСТЬ ПРИМЕНЕНИЯ ЛОГИСТИЧЕСКОГО ПОДХОДА ПРИ СТРОИТЕЛЬСТВЕ ЭНЕРГЕТИЧЕСКИХ ОБЪЕКТОВ
}

\author{
Т.Ф. МАНЦЕРОВА \\ канд. экон. наук, доцент,
} заведующий кафедрой «Экономика и организация энергетики» Белорусского национального технического университета, г. Минск

\author{
Е.П. ЧИЖ \\ магистрант \\ Белорусского национального технического университета, г. Минск
}

\begin{abstract}
Аннотация
Энергетика имеет специфические особенности, отличающие ее от других видов экономической деятельности. Это, прежде всего, технологические особенности. Важное значение имеют и внутриотраслевые особенности энергетики такие как, высокая кониентрачия производства в пределах одного предприятия и одновременно рассредоточение энергетических предприятий с единым технологическим прочессом на больших территориях; жесткая зависимость режима работы энергетических предприятий друг от друга; высокая фондоемкость, длительные сроки службь энергетических предприятий и т.n. Основными признаками, которые определяют энергетику, как монополию, являются большая капиталоемкость; наличие тесной и непосредственной связи с потребителем; производство продукции в конкретных географических точках; обеспечение жизнеспособности общества; неэластичный спрос на товар (энергию).

Ключевые слова: логистика, логистический подход в энергетике, энергетика, строительство энергетических объектов.

Abstract

Energy (power engineering) has unique features which distinguish it from other economic activities. This is primarily a technological features. Special significance have such features as high concentration among energy production within the enterprise, and at the same time, distribution of energy enterprises with a single process at large areas; the rigid dependence of the energy enterprises from each other; a high capitalization ratio, long service time of energy providers, etc. The dominant characteristics that define energy as a monopoly, are the greater capital intensive; the close and direct
\end{abstract}


relationship with the consumer; production in specific geographic locations; social security; inelastic demand for goods (energy).

Key words: logistics, logistics approach in energy, energy, construction of energy facilities.

\section{ВВЕДЕНИЕ}

Энергосистема как топливно-энергетический комплекс охватывает энергетические ресурсы, выработку, преобразование, передачу и использование различных видов энергии.

По мнению А.М. Тлепцерищева, принципы и методы логистики по своей сущности являются универсальными, но их применение в конкретной отрасли требует определенной адаптации. В результате такой адаптации формируется отраслевая логистика. При всем разнообразии толкований логистики в них прямо или опосредованно присутствуют определяющие понятия - поток и управление. Данное обстоятельство предопределяет условие логистизации управляемого процесса.

Под логистизацией понимается процесс формирования потока или представление управляемого объекта в виде потока для оптимизации его параметров. Так, например, Е.К. Ивакин формулирует цели логистизации:

- повышение качества и конкурентоспособности;

- снижение затрат на содержание запасов и иммобилизацию средств организации; рынка;

- рост адаптивности производства к изменяющейся конъюнктуре

- сокращение потерь несопряженности потоков [1].

На основании выполнения логистизации разрабатывается концепция, формируются логистические цепи и системы.

\section{РЕЗУЛЬТАТЫ И ИХ ОБСУЖДЕНИЕ}

В нынешнем столетии место и роль Республики Беларусь в мировой экономике в условиях, когда практически отсутствуют собственные источники углеводородного сырья и металлов, будут во многом определяться уровнем ее научно-технического развития, способностью создавать и эффективно реализовывать собственные инновационные технологии и при необходимости быстро их внедрять, производить товары с высокой добавленной стоимостью.

Энергетический сектор Беларуси составляет 30\% промышленности это целый ряд предприятий и отраслей, производящий $10 \%$ ВВП и экспортирующий более $30 \%$ всего белорусского экспорта. 
Потребление электроэнергии в республике в 2020 году планируется возрасти до 41 млрд кВтч (на 23\% выше уровня 2000 г.). Импорт электроэнергии не превысит 4 млрд кВтч и в зависимости от конъюнктуры рынка может быть прекращен, поскольку установленная мощность собственных генерирующих источников позволит обеспечить необходимый объем производства электроэнергии. В перспективе, будет осуществлен переход от вертикально-интегрированной к рыночной структуре управления энергетикой. Это вызовет кардинальные изменения в экономике энергетики. Формирование обоснованных тарифов, отказ от перекрестного субсидирования - все это потребует снижения себестоимости электрической и тепловой энергии, которое будет осуществляться за счет реализации энергоснабжающими организациями эксплуатационно-технических, ремонтных и энергосберегающих мероприятий, сокращения косвенных (административно-управленческих) и прочих расходов, включаемых в затраты на производство энергии.

В целях повышения энергоэффективности при производстве, передаче и распределении электрической и тепловой энергии предусматривается: снижение удельных топливных затрат на производство электрической и тепловой энергии за счет модернизации неэкономичных морально и физически устаревших основных средств; реконструкция и строительство системообразующих и распределительных электрических и тепловых сетей с применением современных технологий и оборудования; развитие существующих и проектирование новых автоматизированных систем управления технологическими процессами тепловых сетей; использование новых подходов в организации технологического процесса производства энергии, таких как логистика.

Сейчас на балансе РУП «Минскэнерго» находятся более 190 агрегатов тепломеханического оборудования, в том числе: энергетических паровых котлов - 20; паровых турбин - 25; газовых турбин - 5; котлов-утилизаторов - 5; водогрейных котлов -77 ; паровых котлов малой мощности - 57; турбодетандерных установок - 2; когенерационных установок -2 .

В связи с ростом потребления электроэнергии населением и реальным сектором экономики, необходим ввод новых мощностей и реконструкция и модернизация существующих. Это обусловлено износом основного оборудования. На сегодняшний день существует два основных способа строительства и реконструкции энергетических объектов:

- строительство (полный спектр услуг «под ключ» с применением логистики);

- $\quad$ строительство (с разделением выполняемых работ).

Энергетическая логистика - это наука об управлении и оптимизации потоков электричества, газа, воды, тепла, нефти и др., транспортируемых 
неподвижным транспортом потоков соответствующих услуг, а также связанных с ними информационных и финансовых потоков в соответствующих системах электро-, газо-, водо-, тепло- нефтеи другого снабжения, химической промышленности и других непрерывных производствах, где используется большое количество совместно работающего оборудования для достижения поставленных перед ними целей [2].

Формирование в настоящее время долгосрочной логистической стратегии энергетики является главной задачей перспективного развития инновационной деятельности Белоруской энергетической системы.

Основная особенность энергетики - это непрерывность и совпадение во времени процессов генерации, передачи, распределения и сбыта энергии. Все это является предпосылками главных технических и организационных проблем энергетики. Энергию возможно производить, но нельзя складировать. При краткосрочном и среднесрочном планировании в энергетике нельзя ориентироваться на показатель усредненной мощности, так как возможна вероятность неравномерного режима энергопотребления. Это существенное отличие предприятий энергетики от иных предприятий как реального сектора экономики, так и сферы обращения, нацеленных на равномерный и ритмичный режим деятельности, обеспечивающий стабильный финансовый результат. Диспетчеризация энергетических потоков обеспечивает оперативное и надежное снабжение потребителей энергией, так как при отключениях, сбоях в работе оборудования или в случае аварии потребители могут недополучить электроэнергию или быть отключенными от энергосистемы полностью. Именно поэтому, энергетика по своей физической сути функционирует как потоковый процесс. В этой связи, группировка потоков энергии является объектом товародвижения и основой формирования логистической системы энергетики.

Энергетика, как особый вид экономической деятельности в условиях рынка, накладывает свои специфические, обусловленные особенностями технологического цикла производства энергии, особенности в управлении и оптимизации материальных, энергетических и финансовых потоков (рисунок 1).

Технологический цикл производства энергии включает неразрывную цепь последовательных этапов - генерация, передача, распределение и сбыт энергии. Для осуществления первого этапа- генерации- необходимо получение средств производства и предметов труда (материальные потоки), финансирования (государственного, частного, самофинансирования), трудовых ресурсов. В результате производства энергетические объекты производят товар (электро- и теплоэнергию), 
который в дальнейшем по технологической цепочке передается и распределяется посредством сетей. В дальнейшем, осуществляется сбыт энергии потребителям, осуществляется реализация товара и финансовые потоки должны обеспечить возобновление нового цикла за счет новых материальных потоков и финансирования.

Взаимодействие внешней и внутренней среды энергетических предприятий предполагает взаимосвязь между материальными и энергетическими потоками, а также финансированием, рисунок 1.

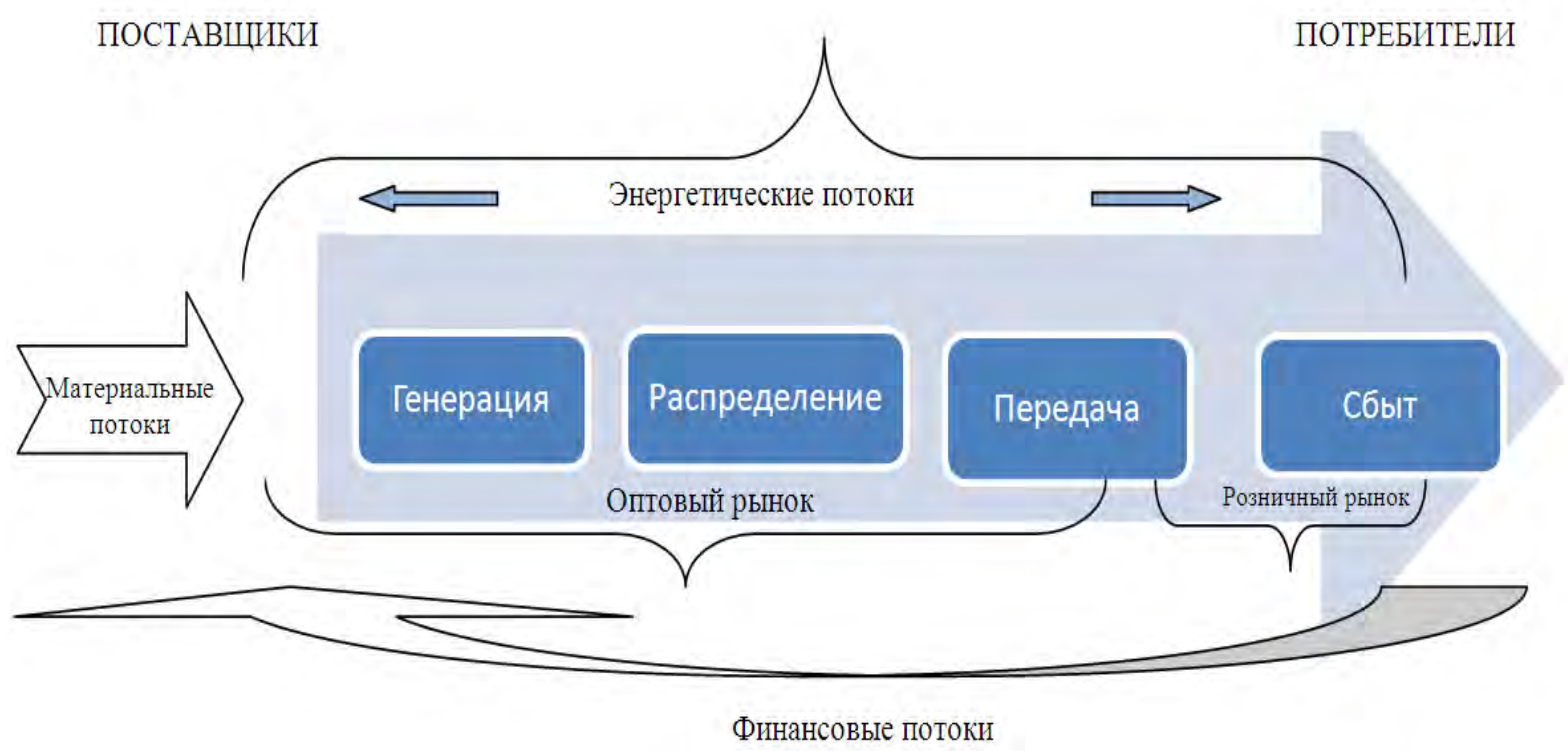

Рисунок 1 - Взаимосвязь потоков в энергетической логистике

Своевременное получение средств за потребленную энергию гарантирует бесперебойное снабжение предприятий энергетики необходимыми ресурсами в требуемом объеме и ассортименте. Структура материальных потоков в энергетике представлена в основном топливом и оборудованием, поэтому особое значение имеет качественная поставка необходимого оборудования.

Цепь поставок оборудования для предприятий энергетики включает в себя логистического посредника, который может быть представлен логистической компанией в энергетике. В перспективе данная компания будет сотрудничать с поставщиками оборудования (как иностранными, так и отечественными), с производителями оборудования, с проектными организациями, с заказчиками. В тоже время, логистический посредник будет сотрудничать с финансовыми институтами и инвесторами, тем самым обеспечивает финансовое посредничество и поддержу заказчику (рисунок 2). 


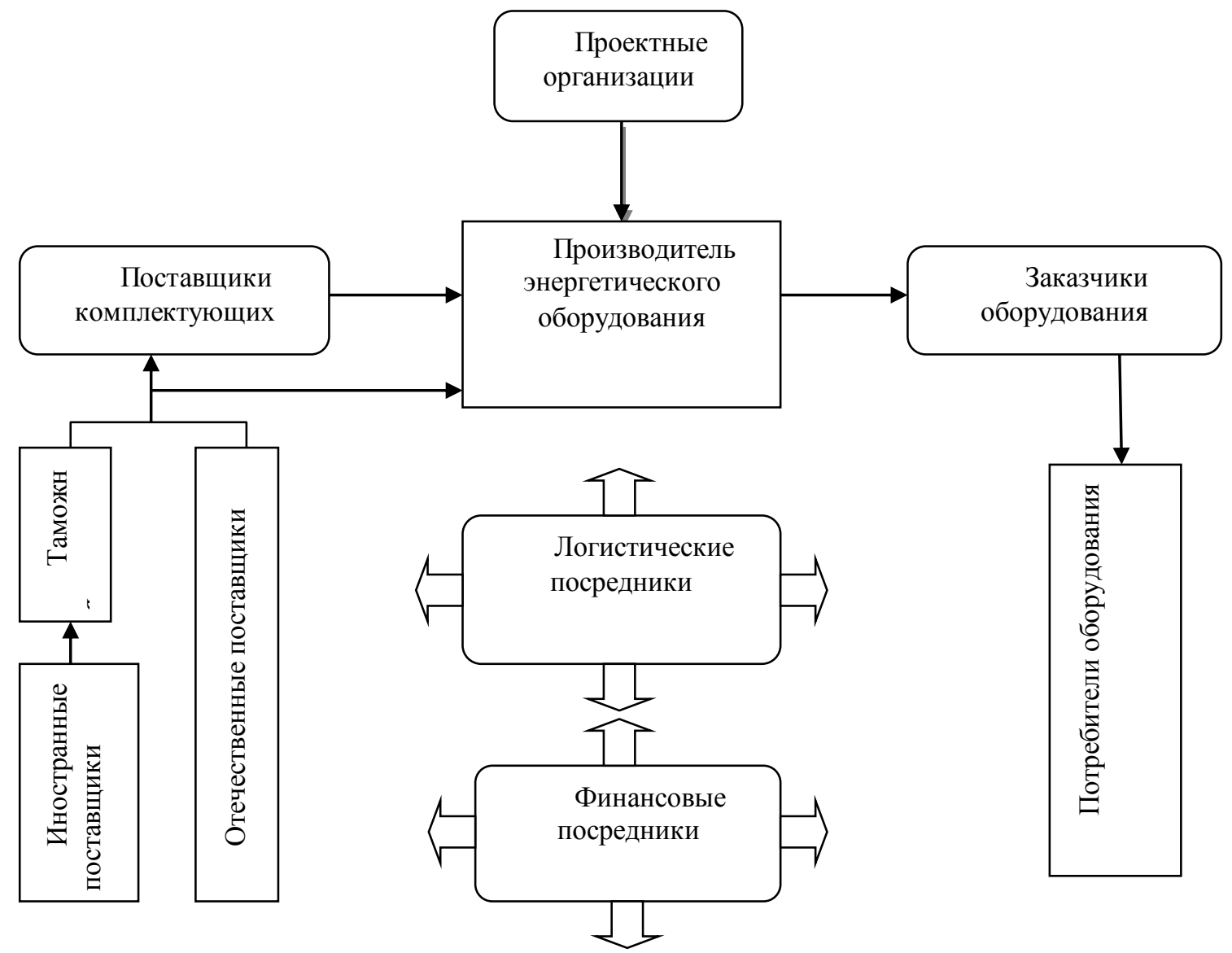

Рисунок 2 - Цепь поставок оборудования для предприятий энергетики

Современное энергетическое предприятие, функционирующее в условиях рынка, опирается на основные принципы маркетинга и логистики. Логистика для энергетического предприятия может быть представлена этапом подготовки ресурсов и этапом подготовки средств производства.

Особое значения для энергетических предприятий имеет этап подготовки средств производства, так как строительство, обновление и модернизация объектов имеет важное значение для эффективного электроснабжения потребителей.

Структура затрат на ремонтное обслуживание по видам основных средств РУП «Минскэнерго» приведена на рисунке 3. Как видно из диаграммы, наибольший удельный вес в затратах на ремонтное обслуживание РУП «Минскэнерго» занимают расходы на ремонтное обслуживание теплотехнического оборудования. 

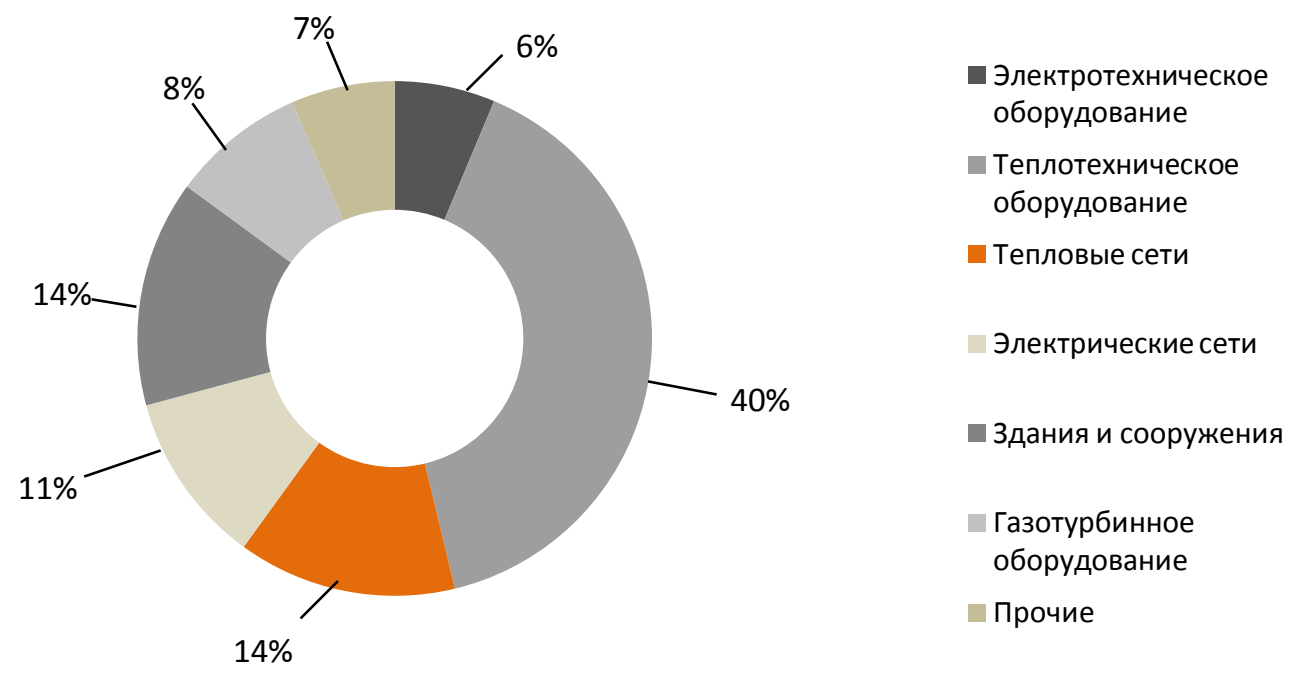

Рисунок 3 - Структура затрат на ремонтное обслуживание

Особое внимание в РУП-облэнерго уделяют ремонту находящихся на балансе тепловых сетей. Менее затратно ремонтное обслуживание газотурбинного и электротехнического оборудования. В отчетном периоде в филиалах РУП «Минскэнерго» было запланировано проведение ремонтов 56-ти агрегатов, в том числе:

- 11 капитальных ремонтов (7 котлов, в т.ч. 5 энергетических, 2 водогрейных; 4 турбины);

- 13 средних ремонтов, (1 переходящий с 2014) (11 котлов в т.ч. 4 энергетических, 1 водогрейный, 6 паровых; 2 паровые турбины);

- 32 текущих ремонта.

В современных экономических условиях республике требуется создание групп компаний в области энергетической логистики. Рассмотрим возможность создания группы компаний «Energy logistics», обеспечивающей строительство и модернизацию энергетических объектов. В состав персонала компании должны быть включены специалисты в области финансов, проектирования, логистики, технического сопровождения и продаж, способные оказывать поддержку клиентам и партнерам на всем пути следования оборудования от завода до конечного потребителя. На сегодняшний момент группа компаний должна представлять собой сеть предприятий, партнеров и дилеров, обеспечивающих товаропроводящую сеть.

Данной группе компаний следует использовать передовые технологии логистики. Благодаря своей структуре, она сможет обеспечить своим клиентам практически любые схемы контрактов, включая прямые поставки из Европейского союза. Так же «Energy logistics» сможет предложить клиентам и партнерам различные финансовые программы от ведущих европейских и белорусских банков. Energy logistics 
предоставляет клиентам полное сопровождение: обработка заказов; логистика; техническое сопровождение; гарантийное и сервисное обслуживание; маркетинг и реклама; услуги по сертификации и лицензированию; обеспечение взаимодействия с клиентами; проектирование; монтаж и пусконаладочные работы.

Группа компаний Energy logistics будет осуществлять следующие функции (рисунок 4):

- организация и обеспечение технического сопровождения поставленного оборудования;

- $\quad$ обработка поступающих от партнеров заказов на оборудование и организация поставок;

- обеспечение гарантийного сопровождения поставляемого оборудования и обработки гарантийных случаев;

- маркетинговые и рекламные мероприятия, способствующие продвижению марки на рынке Республике Беларусь;

- $\quad$ организация и аттестации технических специалистов;

- сотрудничество с органами сертификации и лицензирования в целях организации получения требуемых разрешений на реализацию и эксплуатацию оборудования в Республике Беларусь и ЕС;

- $\quad$ взаимодействие с фирмами - партнерами на рынке Республике Беларусь в целях организации и расширении сети продаж оборудования;

- комплексное строительство энергетических объектов «Под ключ»;

- техническая поддержка при монтаже и пусконаладке оборудования в форме шеф-монтажа и шеф-наладки;

- $\quad$ изготовление частей и элементов оборудования. 


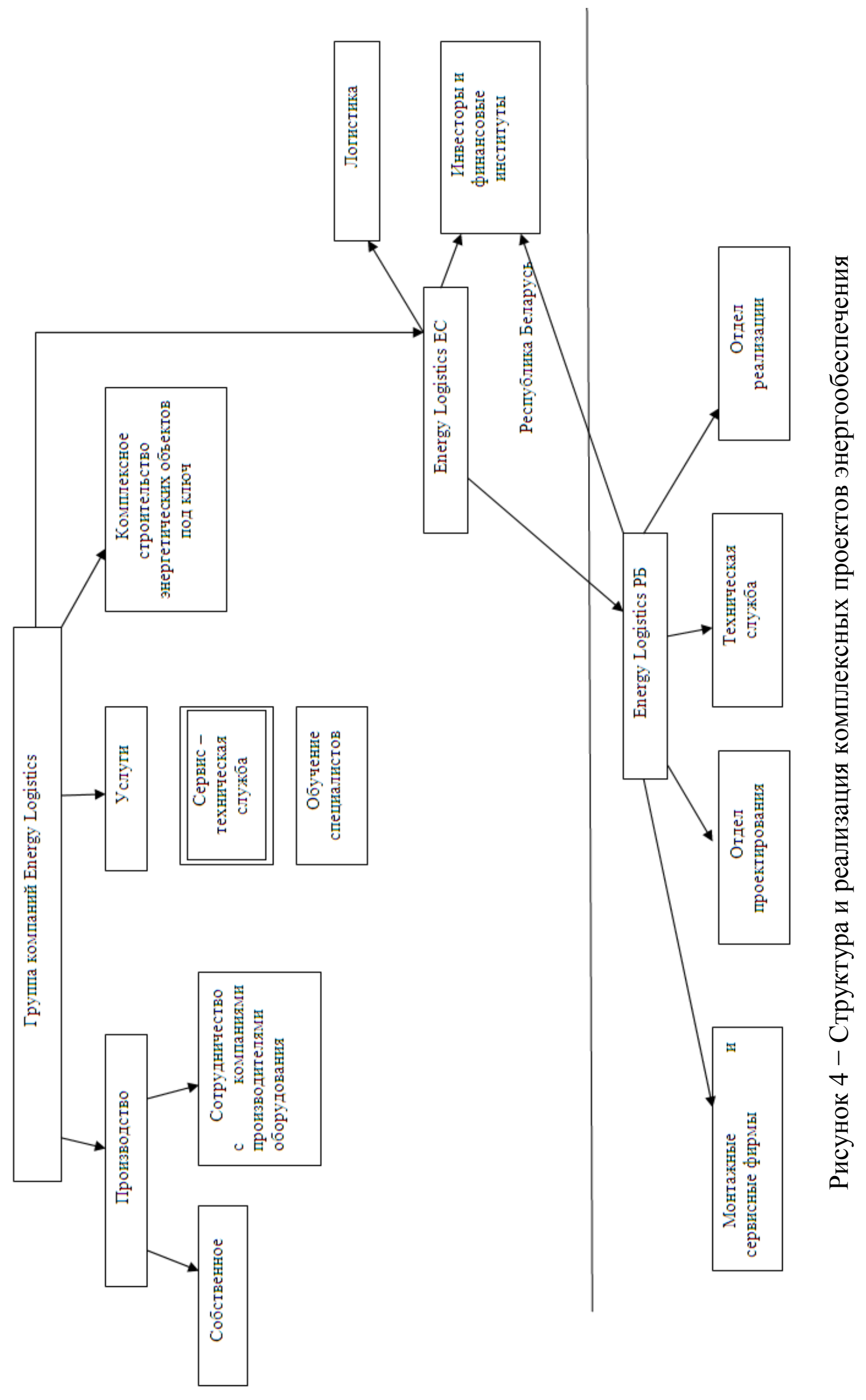




\section{ВЫВОДЫ}

В целях организации финансовой поддержки и инвестировании крупных проектов предприятию необходимо сотрудничать с банковскими и кредитными институтами, через которые организуется финансовые инвестирование и выделяются кредитные линии для реализации проектов большой энергетики, таких как строительство биогазовых установок, подстанций и других энергетических объектов в Беларуси.

Перспективное развитие энергетики невозможно без применения новых подходов и методов, поэтому использование логистических посредником при строительстве энергетических объектов позволит осуществить строительство объектов в оптимальные сроки и с наименьшими затратами.

\section{ЛИТЕРАТУРА}

1. Ивакин, Е.К. Логистика капитального строительства в регионе. Ростов н/Д: Изд-во Ростов. ун-та, 1997. 188 с.

2. Шуртухина, И.В. Логистика в энергетике: Учеб. пособие/ ГОУВПО «Ивановский государственный энергетический университет им. И. В. Ленина»/ И.В. Шуртухина. - Иваново,2008. - 236 с.

3.Сергеев, В.И., Кизим, А.А., Эльяшевич, П.А. Глобальные логистические системы. СПб.: Бизнес-пресса, 2001. - 240 с.

4.Современные логистические технологии и стратегии (электроэнергетический комплекс): [Текст] монография А.У. Альбеков, Т.В. Пархоменко, А.А. Полуботко; Рост. Гос. Эконом. Ун-т (РИНХ). Ростов н/Д, 2010. - 364 с. ISBN 978-5-7972-1607-0.

5. Государственное регулирование экономики и повышение эффективности деятельности субъектов хозяйствования: сб. науч. Статей / Академия управления при Президенте; редкол.: И.И. Ганчерёнок [и др.]. Минск: Академия управления при Президенте, 2015. - 195 с.

6. Тяпухин, А.И. Потоки логистические и не логистические // Риск. 2004. - №1. - C. 15-21

Статья поступила в редакиии. 26 июля 2016 года. 